\title{
KONSTRUKSI JENDELA BAJA \\ BALAI KOTA MALANG
}

\author{
Nurachmad Sujudwijono, Edi Hari Purwono, Totok Sugiarto \\ Staf Pengajar Jurusan Arsitektur, Fakultas Teknik, Universitas Brawijaya Malang
}

\begin{abstract}
ABSTRAK
Material baja merupakan salah satu material yang sudah terkenal sejak jaman dulu, dimana material ini banyak digunakan ketika masa arsitektur klasik, umumnya pada bangunan perkantoran. Dewasa ini aplikasi baja untuk kusen dan profil jendela jarang ditemui, umumnya baja digunakan untuk sistem struktur berupa kolom, balok dan atap pada bangunan. Hal ini dikarenakan baja tidak tahan terhadap karat sehingga biaya perawatannya sulit dan mahal. Penelitian ini bertujuan untuk mengetahui teknik sambungan jendela baja pada bangunan Balai Kota Malang, mengetahui kelebihan-kelebihan baja sebagai teralis jendela pada bangunan Balai Kota Malang. Metode penelitian yang digunakan yaitu metode deskriptif, dengan metode analisis data yang meliputi analisis kritik normatif dan analisis komparatif. Hasil dari penelitian diharapkan dapat menjadi sumber pembelajaran di perkuliahan terkait dengan struktur dan konstruksi bangunan.
\end{abstract}

Kata kunci : jendela, baja, Balai Kota Malang

\begin{abstract}
Steel material is a material that has been famous since ancient times, where the material is mostly used when the classical architecture, generally in office buildings. Today the application of steel for the frame and window profiles are rarely encountered, generally used for steel structural system in the form of columns, beams and roof of the building. This is because steel is not resistant to rust, so the cost of treatment is difficult and expensive. This study aims to determine the connection technique steel windows in Malang City Hall building, knowing the advantages of steel as a window grille at Malang City Hall building. The method used is descriptive method, the method of data analysis which includes critical analysis of normative and comparative analysis. The results of the study is expected to be a source of learning in lectures related to the structure and construction of buildings.
\end{abstract}

Keywords: window, steel, Malang City Hall

\section{Pendahuluan}

Material baja merupakan salah satu material yang sudah terkenal sejak jaman dulu, dimana material ini banyak digunakan ketika masa arsitektur klasik, umumnya pada bangunan perkantoran. Kelebihan material baja ini adalah sifatnya yang awet/tahan lama, baja juga memiliki kelebihan dalam pemasangan dan daur ulang bahan.

Dewasa ini aplikasi baja untuk kusen dan profil jendela jarang ditemui, umumnya baja digunakan untuk sistem struktur berupa kolom, balok dan atap pada bangunan. Hal ini dikarenakan baja tidak tahan terhadap karat sehingga biaya perawatannya sulit dan 
mahal. Namun, seperti pada Balai Kota Malang, baja digunakan sebagai profil kusen dan profil jendela, dimana sistem sambungan menggunakan sistem sambungan untuk kusen baja pada umumnya.

Seperti halnya kebanyakan kota-kota lain di Indonesia pada umumnya, Kota Malang modern tumbuh dan berkembang setelah hadirnya administrasi desentralisasi kolonial Hindia Belanda. Begitu juga dengan bangunan Balai Kota Malang yang berada di Jalan Tugu Malang, yang dibangun tahun 1929 rancangan HF Horn dari Semarang. Bangunan ini pernah terbakar yang menyebabkan kerusakan bangunan Balai Kota Malang dan kemudian dilakukan renovasi pada tahun 2002. Sampai sekarang, bangunan ini masih mempertahankan gaya arsitektur klasik dengan konstruksi jendela baja peninggalan kolonial Belanda yang saat ini hanya terdapat pada bangunan depan Balai Kota Malang.

Tujuan dari penelitian ini adalah untuk mengetahui teknik sambungan jendela baja pada Gedung Balai Kota Malang. Setelah diuraikan bagaimana teknik sambungan pada kusen jendela baja, maka kita juga akan mengetahui kelebihan-kelebihan baja jika digunakan sebagai teralis jendela pada Gedung Balai Kota Malang.

\section{Metode}

Metode penelitian ini menggunakan metode deskriptif-analisis yakni suatu metode yang menggunakan penjelasan data berupa kondisi objek penelitian yang telah diperoleh melalui hasil survey lapangan, yaitu pengamatan langsung dan wawancara. Kemudian melakukan analisa terhadap data yang sudah diperoleh untuk mencapai tujuan. Selain itu dalam meneliti dibutuhkan cara dengan mengumpulkan data yang berasal dari naskah wawancara, catatan lapangan, foto, video tape, catatan, memo, dan dokumen resmi lainnya.

\subsection{Tahapan Penelitian}

Persiapan dimulai dengan membuat time schedule untuk menentukan target kemajuan penelitian per minggu. Tahap berikutnya adalah tahap pengumpulan data. Teknik - teknik pengumpulan data yaitu dengan:

1. Mengumpulkan catatan pengamatan dengan melakukan observasi sebagai pengamat

2. Melakukan wawancara terbuka secara tidak terstruktur dan mengambil catatan wawancara.

3. Melakukan wawancara terbuka secara tidak terstruktur, audiotape untuk wawancara, mencatat interview serta membuat catatan selama melakukan penelitian.

4. Survei literatur. Penggalian data-data (tampak, potongan, detail, dan foto-foto, jendela baja) mengenai objek penelitian melalui studi literatur (internet, buku, dll)

Jika dikategorikan berdasarkan dua jenis data yaitu data primer dan data sekunder, maka metode pengumpulan data mencakup:

1. Survei Data Primer

Metode pengambilan data dilakukan dengan observasi, pengambilan foto atau gambar, dan melakukan wawancara tidak terstruktur. Dalam penelitian naturalistik kualitatif, peneliti sendiri harus memasuki lapangan untuk mengumpulkan data melalui observasi dan wawancara.

2. Survei Data Sekunder

Data sekunder disini yaitu dengan pengumpulan data - data dari studi literatur. Pengumpulan data tersebut dengan cara mencari literatur yang berkenaaan dengan studi yang diangkat atau dipermasalahkan.Data tersebut bisa didapat melalui 
browsing internet, studi-studi dari hasil penelitian sejenis atau yang mendekati, dan juga dokumen-dokumen resmi yang dikeluarkan oleh pihak terkait. Studi-studi terdahulu dapat berupa jurnal. Adapun literatur berupa buku-buku, serta artikelartikel yang berhubungan dengan objek dan permasalahan yang diangkat.

Terdapat bermacam-macam dokumen dalam penggunaan data sekunder. Dokumen terdiri atas tulisan pribadi seperti dokumen resmi. Dokumen, surat- surat, foto, dan lainya dapat dipandang sebagai "nara sumber" yang dapat dimintai menjawab pertanyaan-pertanyaan yang diajukan oleh peneliti.

Setelah data dikumpulkan dan dikompilasi, dilakukan analisis data. Metode analisis data yang digunakan adalah:

1. Metode kritik normatif, metode ini menilai sistem konstruksi jendela baja pada bangunan berdasarkan prinsip-prinsip konstruksi jendela baja yang ada.

2. Metode komparatif dimana teori yang didapat pada metode kepustakaan menjadi dasar untuk menganalisa data yang didapat dari lapangan. Pencocokan data dengan mencocokan data antara data primer dengan sekunder, yang mana data sekunder sebagai rujukan dalam menganalisa. Setelah dianalisis, dari hasilnya didapatkan suatu kesimpulan yang dapat mewadahi tujuan penulisan.

\subsection{Deskripsi Variabel}

Penelitian ini memfokuskan pada konstruksi jendela baja. Yang meliputi:

1. Teknik sambungan antara kusen dan dinding

2. Teknik sambungan antara profil kusen jendela baja dan bingkai jendela baja

3. Teknik sambungan antara profil kusen jendela baja dan bingkai jendela kayu

4. Kelebihan dari konstruksi jendela baja.

\section{Hasil dan Pembahasan}

3.1 Kusen Jendela Baja Balai Kota Malang

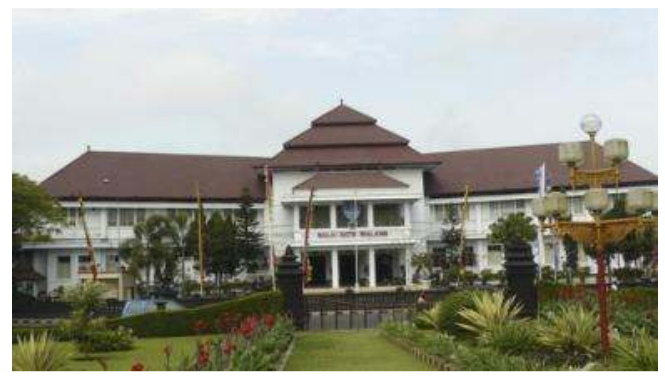

Gambar 1. Balai Kota Malang

Pada bangunan Balai Kota Malang, konstruksi jendela yang menggunakan baja terletak pada massa bangunan bagian depan bangunan. Dari hasil studi lapangan terdapat 20 jumlah jendela yang masih menggunakan baja sebagai sistem konstruksi jendela. 


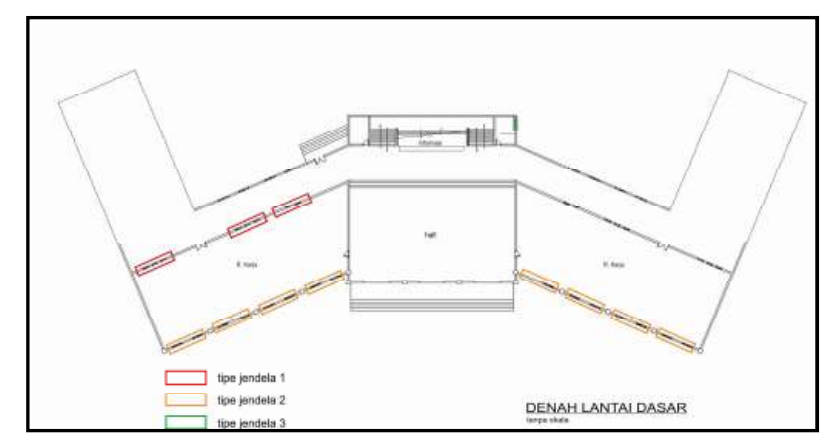

Gambar 2. Denah Lantai Dasar Objek Studi Jendela Baja

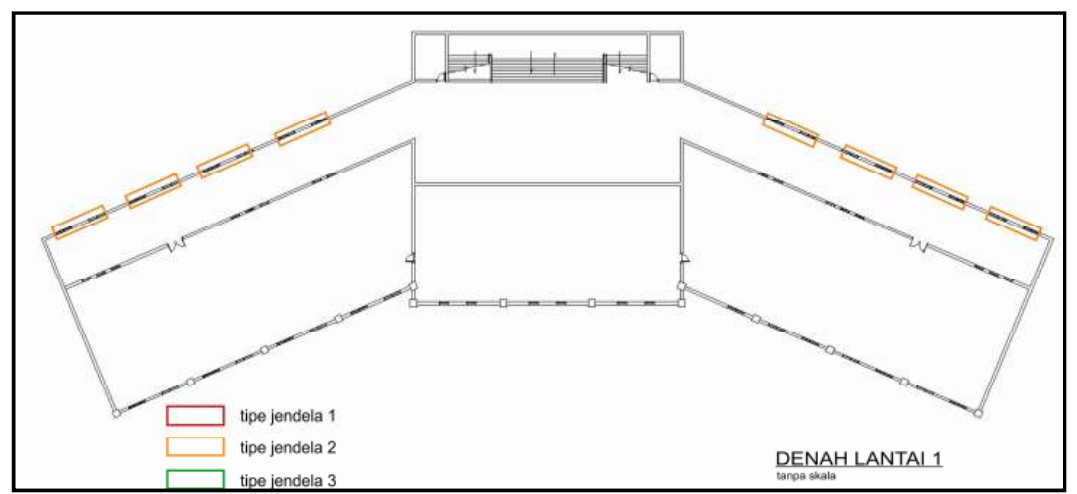

Gambar 3. Denah Lantai Satu Objek Studi Jendela Baja

\subsection{Jendela Baja Balai Kota Malang}

Pada masa pembangunan Balai Kota Malang yaitu pada tahun 1927-1929an arsitektur gaya kolonial Belanda mengalami perkembangan yang pesat sehingga banyak diterapkan pada bangunan-bangunan penting pada saat itu. Adapun bangunanbangunan yang di bangun pada tahun 1920-1940an dengan gaya arsitektur Kolonial Belanda antara lain :

1. Zusterschool (Jl. Tjelaket- dibangun antara th. 1926 arsiteknya Hulswit, Fermont \& Ed.Cuypers)12

2. Fraterschool (Jl. Tjelaket, dibangun antara tahun 1926, arsiteknya Hulswit, Fermont \& Ed.Cuypers)

3. Komplek pertokoan di perempatan Jl. Kayutangan (dibangun ahun 1936, arsiteknya Karel Bos)

4. Gedung HBS/AMS di J.P. Coen Plein (alon-alon bunder, dibangun tahun 1931, arsiteknya Ir. W. Lemei)

5. Theresiakerk (gereja Santa Theresia) di depan Boeringplein (taman Buring) dibangun th. 1936, arsiteknya Rijksen en Estourgie.

Pemakaian profil baja pada kusein jendela di Gedung Balai Kota Malang merupakan pilihan desainer dari Belanda pada saat itu untuk mempertahankan dan memperkuat ciri dan karakter bangunan Kolonial Belanda. Pemilihan profil baja saat itu menurut sumber yang dipercaya, dikarenakan banyaknya bahan (profil) yang tersedia untuk mengembangkan bangunan-bangunan perkantoran milik Belanda.

Pada bangunan Balai Kota Malang terdapat 20 buah jendela yang menggunakan baja sebagai sistem konstruksi jendela. Dari 20 buah jendela tersebut dibagi menjadi 3 
tipe berdasarkan ukuran dan model jendela serta bukaannya. Pada tiap tipe jendela akan dijelaskan teknik sambungan yang digunakan, yakni sebagai berikut:

JENDELA 1 :

Tipe jendela 1 merupakan jendela yang berputar ke dalam pada bagian jendela atas dan berputar keluar pada bagian jendela bawah. Tipe jendela 1 ini dibagi menjadi dua tipe ukuran jendela yakni tipe jendela 1a yang ukurannya lebih besar dibandingkan dengan tipe jendela $1 b$.

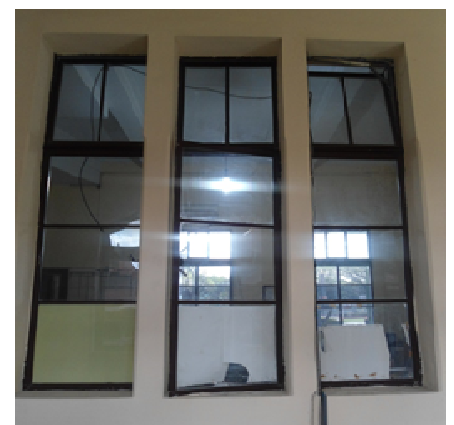

Gambar 4. Jendela Tipe 1a

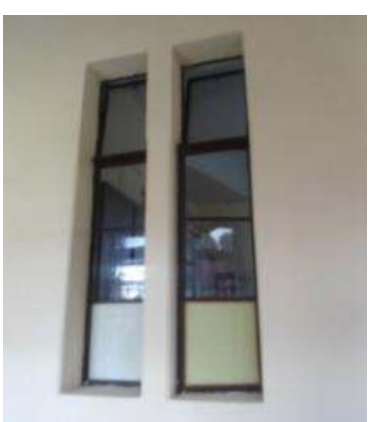

Gambar 5. Jendela Tipe 1b
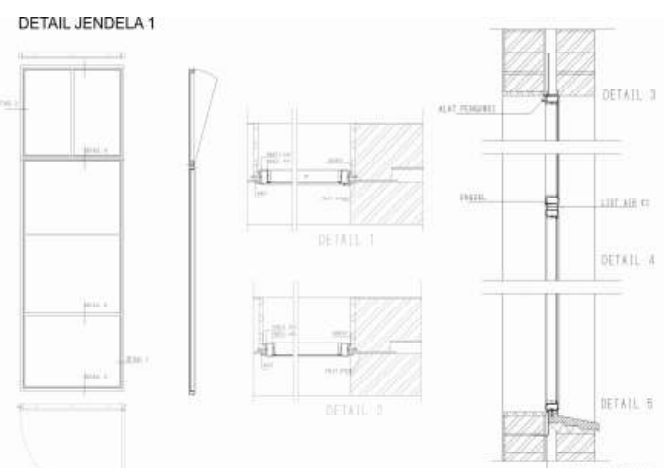

Gambar 6. Detail Jendela Tipe 1

JENDELA 2 :

Merupakan jendela dengan double shading yaitu terdapat dua buah jendela, dimana jendela bagian dalam adalah jendela yang berputar ke dalam (pada bagian bawah), sedangkan pada bagian atas jendela terdiri dari jendela mati dan jendela nako. Jendela pada bagian luar merupakan jendela yang berputar ke luar yang terdiri dari profil kusen dan profil list baja dengan krepyak kayu miring.

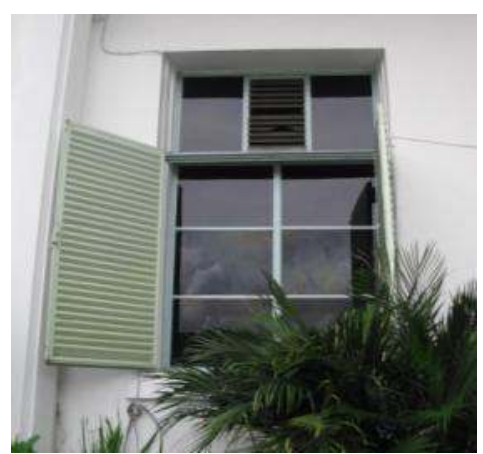

Gambar 7. Jendela Tipe 2 

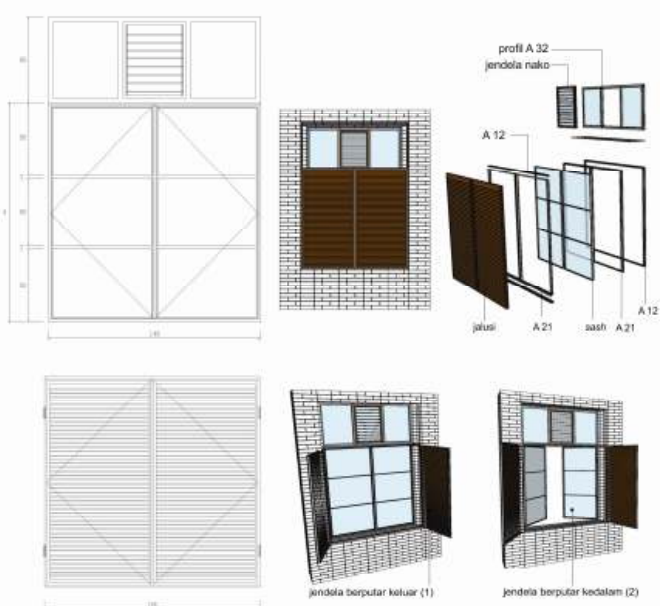

JENDELA 3 :

Gambar 8. Detail Jendela Tipe 2

Merupakan jendela yang sistem bukaannya sama dengan tipe jendela 1 yaitu jendela yang berputar ke dalam pada bagian jendela atas dan berputar keluar pada bagian jendela bawah. Yang berbeda adalah jenis list profil jendela yang berbahan kayu.

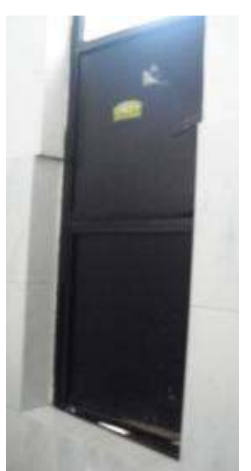

Gambar 9. Jendela Tipe 3

Profil-profil tambahan pada ketiga jendela terdiri dari Profil K1 yaitu sebagai profil pengkopel pada sambungan ataupun penyusunan profil-profil mendatar dalam satu jendela. Di samping itu juga berlaku sebagai list air untuk jendela yang terletak langsung berhubungan dengan area luar ruangan dan untuk mengkakukan jendela yang berukuran besar.

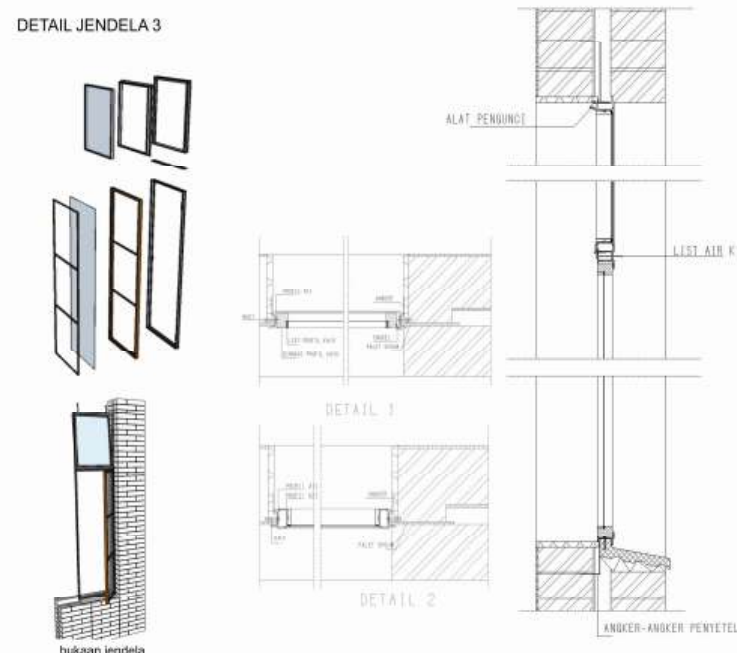

Gambar 10. Detail jendela tipe 3 


\subsection{Sistem Sambungan}

3.3.1 Penyambungan antara dinding dan kusen
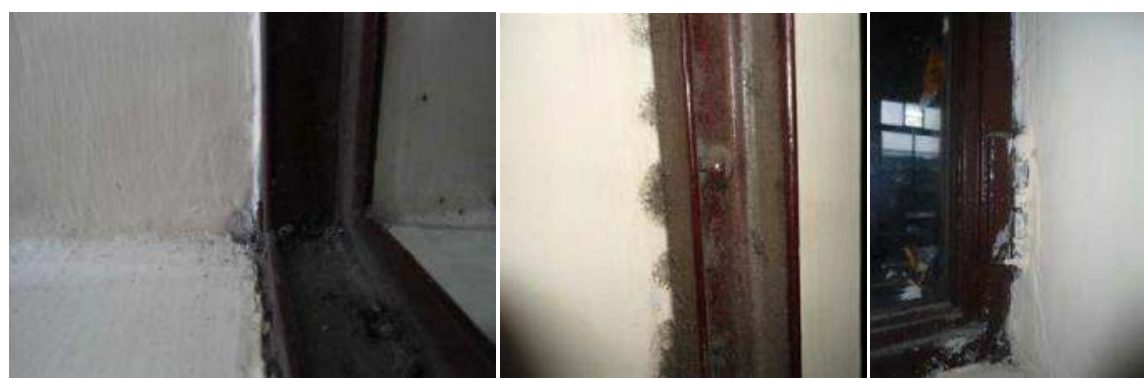

Gambar 11. Penyambungan Antara Jendela dan Dinding

Untuk penyambungan antara kusen dan dinding dilakukan dengan pemasangan angker-angker pada jendela baja, yang ditembok dalam dinding yang kemudian dilanjutkan dengan pemasangan baut. Setelah selesainya pekerjaan tersebut, jendela kaca di pasang belakangan dalam lubang dinding yang telah disediakan.

\subsubsection{Penyambungan antar kusen}

Untuk penyambungan antara kusen dan kusen dilakukan dengan pemasangan engsel yang kemudian di di lanjutkan dengan pemasangan baut pada sambungan antar kosen baja.
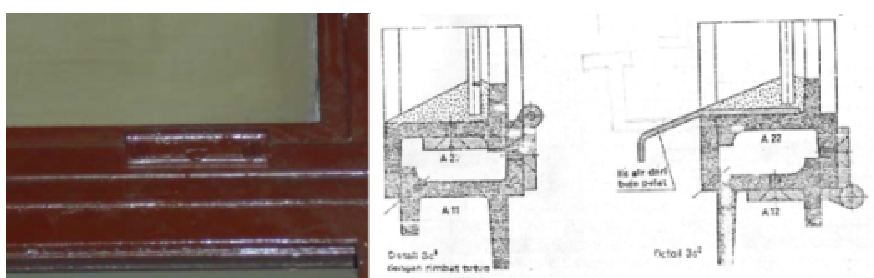

Gambar 12. Sambungan Antar Kusen

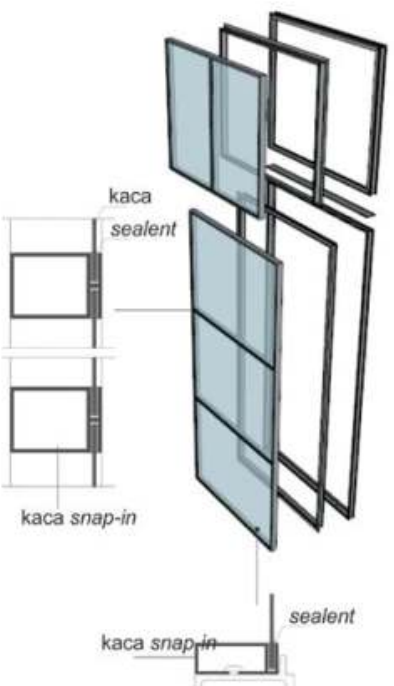

Gambar 13. Sistem Pengacaan 
Alat pengunci pada jendela baja di pasang dengan cara yaitu: yang satu dipasangkan pada kusen ataupun dinding dan paroh yang satunya lagi dipasangkan pada jendela. Untuk penguncian dilakukan dengan sebuah engkol jendela. Jendela dapat dibiarkan terbuka dengan bantuan alat sebuah pembuka jendela.

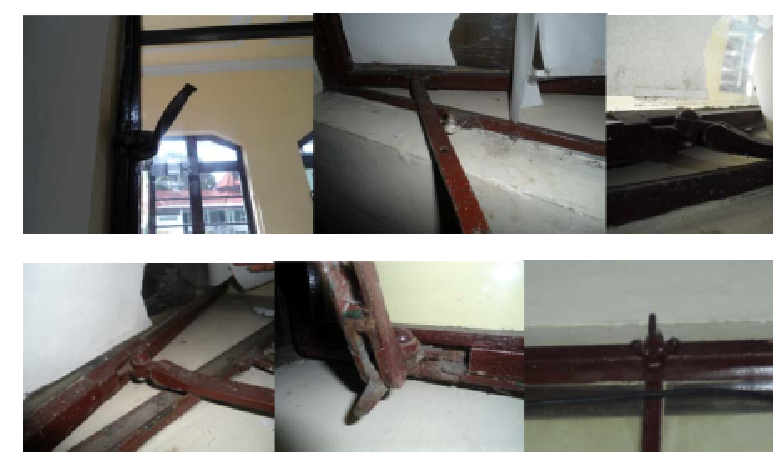

Gambar 14. Alat Pengunci Pada Jendela Baja di Balai Kota Malang

\subsection{Kelebihan Kusen Jendela Baja}

Dari pengumpulan data literatur didapatkan beberapa mengenai penggunaan baja sebagai kusen jendela. Hal-hal yang menguntungkan dibandingkan dengan kusen jendela dan pintu dari kayu, kita akan menemukan hal-hal menguntungkan berikut:

1. Kelebaran yang tidak seberapa dari tiang-tiang dan ambang-ambang, sehingga pemasukan cahaya pada ukuran lubang dinding yang sama akan lebih besar

2. Karena logam lebih tahan terhadap penyusutan maupun pengembangan, celah penyatuan antara kosen dan jendela tidak akan mengalami perubahan yang berarti

3. Pemeliharaan atas jendela-jendela alumunium dan perunggu tidaklah begitu banyak tidak demikian halnya dengan kusen jendela dan pintu yang terbuat dari baja, karena baja tidak tahan terhadap karat dan seperti halnya kayu ia pun harus sering dicat.

Dibandingkan dengan kusen jendela dari kayu, kusen dari bahan baja lebih tahan lama dan tidak mudah keropos. Terbukti pada kusen jendela yang ada pada gedung Balai Kota Malang masih bertahan hingga sekarang. Baja memiliki profil yang kaku dan ramping, sebuah dinding dengan jendela-jendela dan pintu-pintu logam akan nampak lebih dinamis.

Penggunaan kusen pintu dan jendela dengan material baja pada umumnya dilandasi oleh pertimbangan-pertimbangan estetis. Pada gedung Balai Kota ini penggunaan kusen jendela baja menambah nilai estetis yang ada, serta memperkuat kesan bangunan kolonial.

\section{Simpulan}

Balai Kota Malang dibangun tahun 1927-1929, oleh arsitek H.F. Horn. Gaya arsitektur kolonial modern setelah tahun 1920 an di Hindia Belanda pada waktu itu sering disebut gaya "Niewu Bouwen", yang disesuaikan dengan iklim dan teknik bangunan di Hindia Belanda waktu itu. Sebagian besar menonjol dengan ciri-ciri seperti : atap datar, gevel horisontal, volume bangunan yang berbentuk kubus, serta warna putih.

Pada Bangunan Balai Kota Malang terdapat 3 tipe jendela baja, yang dibedakan berdasarkan ukuran, material yang digunakan, dan teknik sambungannya. Hal yang perlu diperhatikan dalam teknik sambungan ini adalah masalah kerapatan antar 
material baik antara sambungan kusen dan dinding maupun sambungan kusen dan jendela.

Konstruksi jendela baja memiliki beberapa kelebihan antara lain, pemasangan yang mudah, ringan dan lebih tahan lama dibanding konstruksi kayu, hanya saja diperlukan perawatan yang lebih untuk pencegahan karat pada material baja.

Hasil penelitian mengenai konstruksi jendela baja di Balai Kota Malang ini merupakan kompilasi dari konstruksi baja khususnya jendela baja yang diharapkan dapat menjadi sumber pembelajaran di perkuliahan terkait dengan struktur dan konstruksi bangunan mengenai alternatif pemilihan bahan untuk konstruksi kosen jendela.

\section{Daftar Pustaka}

Diraatmadja, E. 1982. Membangun Ilmu Bangunan 2 - Cetakan Keempat. Jakarta: Erlangga. Frick, Heinz. 2003. Ilustrasi Konstruksi Bangunan. Jakarta: Erlangga.

Hardinoto. 1996. Perkembangan Kota dan Arsitektur Kolonial Belanda di Malang. Yogyakarta: Penerbit Andi.

Neutra, Richard. "Lovell House", artikel ini diakses pada 11Agustus 2013 dari http://www.homerika.com/145/lovell-house-richard-neutra/html. 